\title{
Adherence to Antiretroviral Therapy and associated factors among HIV infected children in Ethiopia: unannounced home-based pill count versus caregivers' report
}

Silenat Biressaw ${ }^{1}$, Woldaregay Erku Abegaz ${ }^{2}$, Markos Abebe ${ }^{3}$, Workeabeba Abebe Taye ${ }^{4}$ and Mulugeta Belay²*

\begin{abstract}
Background: The introduction of Antiretroviral Therapy (ART) has brought a remarkable reduction in HIV-related mortality and morbidity both in adults and children living with HIV/AIDS. Adherence to ART is the key to the successful treatment of patients as well as containment of drug resistance. Studies based on caregivers' report have shown that adherence to ART among children is generally good. However, subjective methods such as caregivers' report are known to overestimate the level of adherence. This study determined the rate of adherence and its predictors using unannounced home-based pill count and compared the result with caregivers' report in a tertiary referral hospital in Ethiopia.
\end{abstract}

Methods: A cross-sectional study was conducted between December 1, 2011 and January 30, 2012. The study participants were 210 children on ART and their caregivers attending pediatric ART clinic of Tikur Anbessa Hospital $(T A H)$, Addis Ababa University. Caregivers were interviewed at the ART clinic using a structured questionnaire. Then, unannounced home-based pill count was done 7 days after the interview.

Results: Caregiver-reported adherence in the past 7 days prior to interview was 93.3\%. Estimated adherence using unannounced home-based pill count was found, however, to be $34.8 \%$. On multivariate logistic regression model, children with married [aOR $=7.85$ (95\% Cl: $2.11,29.13)]$ and widowed/divorced $[\mathrm{aOR}=7.14$ (95\% Cl: 2.00,25.46)] caregivers, those who were not aware of their HIV sero-status [aOR $=2.35(95 \% \mathrm{Cl}: 1.09,5.06)]$, and those with baseline WHO clinical stage III/IV [OR $=3.18(95 \% \mathrm{Cl}: 1.21,8.40]$ were more likely to adhere to their ART treatment. On the other hand, children on d4T/3Tc/EFV combination [OR $=0.10(95 \% \mathrm{Cl}: 0.02,0.53)]$ were less likely to adhere to their treatment. Caregivers' forgetfulness and child refusal to take medication were reported as the major reasons for missing doses.

Conclusion: The level of adherence based on unannounced home-based pill count was unacceptably low. Interventions are urgently needed to improve adherence to ART among children at TAH. Besides, a longitudinal study measuring adherence combined with clinical parameters (viral load and CD4 count) is needed to identify a simple and reliable measure of adherence in the study area.

Keywords: Children, HAART, Adherence, Home-based unannounced pill count, Ethiopia

\footnotetext{
*Correspondence: mulg2002@yahoo.com

${ }^{2}$ Aklilu Lemma Institute of Pathobiology, Addis Ababa University, P.O. Box 1176, Addis Ababa, Ethiopia

Full list of author information is available at the end of the article
} 


\section{Background}

HIV/AIDS is one of the most devastating pandemics humanity has ever faced. Globally, about 34 million people were living with the virus in 2010 [1]. In the same year, children contributed to $10 \%$ of the total infected. SubSaharan Africa remains the most hard-hit region accounting for $68 \%$ of the total global burden [1]. Although the prevalence is relatively low, Ethiopia carries one of the largest HIV-infected populations in the world. Out of the 1.1 million people living with HIV, about 72,000 were reported to be children [2].

In an effort to curb the epidemics as well as to improve the quality of life among HIV-infected people, multiple strategies including treatment of patients with ART have been implemented worldwide. The introduction of ART has resulted in a remarkable reduction of HIV-related mortality and morbidity [3-6] as a result of rapid immunological restoration $[3,7,8]$ and viral suppression $[3,8]$.

However, ART provision has major challenges. Despite efforts made over the last decade, universal access to ART especially in low income countries remains low: only half of adults and a quarter of children eligible for ART have started treatment [1]. Among those on ART, retention as well as adherence to therapy remains to be major obstacles for the successful treatment of HIVinfected patients. Adherence to ART is the key to achieving optimal therapeutic effects [9]. Studies indicate that poor adherence is associated with virologic failure $[10,11]$ and increased mortality [12].

Hence, unacceptably high level of virologic failure $[10,13,14]$, limited access to second line drugs in low income countries and the public risk of transmitted resistance as HIV infected children living into adolescence become engaged in sexual relationships make maintaining adherence among children crucial [15]. For optimal therapeutic effect and to minimize HIV drug resistance, patients should have at least $\geq 95 \%$ adherence to ART $[6,11,16]$.

Designing strategies for maintaining optimal level of adherence among children is an essential step towards ensuring treatment success. However, this task requires careful assessment of the status of level of adherence and its predictors among the target population $[6,17]$. In pediatric patients, adherence is more complex as it involves factors related to children, caregivers, family, regimen, society and culture [15,17], and measuring adherence remains a challenge since there is no single method that is reliable and simple [15].

Globally, the level of adherence to ART among HIV infected children varied from $49 \%$ to $100 \%$ [18] depending on the settings and the methods used. The most frequently used measure of adherence in children is self or caregivers' report, and the highest level of adherence
(79.5-100\%) emerged from such measurements [18]. Previous studies among Ethiopian children [19] and adults $[20,21]$ reported a high level of adherence to ART using self /caregivers' report. However, self or caregivers' report method alone, although simple, is subjective and subject to social desirability [17] and recall bias. Pill count is a more objective method to assess medication adherence and is recommended as a standard for clinical practice [22]. Therefore, this study looks into the level of adherence and associated factors among pediatric HIV patients taking ART in a pediatric ART clinic using unannounced home-based pill count and compares the result to caregivers' reported adherence.

\section{Methods}

\section{Study area}

The study was conducted at the pediatric ART clinic of TAH, Addis Ababa University. TAH, located in Addis Ababa, is the single largest referral and tertiary level teaching hospital in Ethiopia. Patients are referred to this hospital from other health institutions across the country. After the government launched free ART in 2005, the hospital started to provide the service to people living with HIV/AIDS including children. The hospital has separate ART clinics for adults and children.

The hospital provides both first line and second line drug regimens. First line regimens that children were taking included $4 \mathrm{a}=\mathrm{d} 4 \mathrm{~T} / 3 \mathrm{Tc} / \mathrm{NVP}$ (Stavudine, Lamivudine, Nevirapine), $4 \mathrm{~b}=\mathrm{d} 4 \mathrm{~T} / 3 \mathrm{Tc} / \mathrm{EFV}$ (Stavudine, Lamivudine, Efavirenz), $4 \mathrm{c}=\mathrm{AZT} / 3 \mathrm{Tc} / \mathrm{NVP}$ (Zidovudine, Lamivudine, Nevirapine), and $4 \mathrm{~d}=\mathrm{AZT} / 3 \mathrm{Tc} / \mathrm{EFV}$ (Zidovudine, Lamivudine, Efavirenz). Some children were also on the following second line regimens: $\mathrm{ABC} /$ ddi/LPv/r (Abacavir, Didanosine, retonavir enhanced Lopinavir), AZT/3Tc/LPv/r (Zidovudine, Lamivudine, retonavir enhanced Lopinavir) and D4T/3TC/LPv/r (Stavudine, Lamivudine, retonavir enhanced Lopinavir). The only liquid formulation available during the study period was $\mathrm{LPv} / \mathrm{r}$ and only one child was taking this formulation as a component of $\mathrm{D} 4 \mathrm{~T} / 3 \mathrm{TC} / \mathrm{LPv} / \mathrm{r}$. The routine laboratory tests included CD4 count, haemoglobin and blood chemistry such as liver function tests. Among these, CD4 count was done every 6 months and the rest were done on the basis of clinical conditions of children.

\section{Study design and study participants}

A cross-sectional study was conducted between December 1, 2011 and January 30, 2012. Since the initiation of free ART programme, a total of 1152 HIV positive children were registered at the pediatric ART clinic of the hospital. Of these children, 751 were started on treatment and 554 of them were on active follow-up during data collection. All children ( $<15$ years) on ART for at least three months and their caregivers were consecutively included until 
sample size was achieved. Children living in an orphanage, those younger than 3 months as well as those living out of Addis Ababa were excluded. Sample size of 210 was calculated using the formula for estimation of single population proportion with $95 \% \mathrm{CI}, 5 \%$ margin of error, estimated adherence level of $86.9 \%$ [19] and a $20 \%$ nonresponse rate.

\section{Method of data collection}

Data collection was done using a pre-tested, structured questionnaire addressing demographic, socioeconomic and disclosure variables of caregivers and children, as well as health care providers and health care system variables. Nine questions were posed to assess knowledge of caregivers about the ART regimen their children were taking and the median score was taken as a cut-off to classify caregivers as having good or poor knowledge. Available clinical (WHO stage) and immunological (CD4 count) data of children were extracted from records. Caregivers were interviewed during routine clinic appointments in a separate room. Care givers' home addresses were recorded at the time of interview after getting permission for a home visit; however, caregivers were not informed regarding pill count until home visit was made to avoid bias. Home-based unannounced pill count was conducted 7 days after interview. To make sure caregivers received the prescribed number of pills from the pharmacy, pill count was done immediately after pills were dispensed. Subsequently, caregivers were instructed to use only the currently dispensed pills and not any pills left at home. Pills left at home were counted separately and were not included in calculating adherence rate. Interview and pill count were done by a trained nurse and one of the authors supervised data collection.

\section{Operational definitions}

Adherence - Adherence to a medication is generally defined as the extent to which patients take medications as prescribed by their health care providers. In HIV treatment, adherence $<95 \%$ is associated with virologic failure [6,11], opportunistic infections and deaths [23], and therefore, in this study a child was said to be adherent if he/she took $\geq 95 \%$ of the prescribed doses for one week prior to the interview or the pill count.

Caregiver - Parent/guardian or person in charge of routinely administering antiretroviral drugs to children on ART.

Good knowledge- If care givers answer 7-9 questions correctly

Poor knowledge- less than 7 questions answered correctly

Biological parents - mother or father of the child
Non- biological parents - Relatives, or those who adopted the child

Baseline CD4 count: CD4 count done when a child started ART

Current CD count: CD4 count done within 6 months of data collection

\section{Data management and analysis}

Data were checked manually, computerized using EPiData version 3.0 and exported to SPSS version 20 for analysis. Chi-square test was used to assess association between adherence and independent variables. The percent of adherence was calculated by dividing the number of doses taken in one week by the total number of doses prescribed for that week. Multivariate logistic regression was done to identify factors independently associated with ART adherence. The association of predictor variables with the dependent variable was described by using 95\% confidence interval (CI) and adjusted odds ratio (aOR). A p-value of $<0.05$ was considered statistically significant.

\section{Ethics statement}

The study was approved by the Institutional Ethical Review Board of Aklilu Lemma Institute of Pathobiology (ALIPB193/2004), Institutional Ethical Review Board of Medical Faculty, Addis Ababa University (085/11/ped) and Armauer Hansen Research Institute and All Africa Leprosy, Tuberculosis and Rehabilitation Training Centre Ethical Review Committee (Po09/12). Written informed consent was obtained from all caregivers and verbal assent was obtained from children who were aware of their sero-status.

\section{Results}

\section{Socio-demographic characteristics of caregivers and} children

A total of 238 primary caregivers were interviewed of whom 28 refused home visit, making the response rate for pill count $88 \%$. Hence, 210 caregivers were included in the final analysis. The median age of caregivers was 38(IQR 30.8-49) years; and the majority (84.8\%) of them were females. Of the 210 children, 109 (51.9\%) were males and the median age was 11 (IQR 8-13) years, the vast majority $(74.8 \%)$ being 9 years or older. The majority of the caregivers were literate and with a monthly income less than 30 USD. More than half of the caregivers were biological parents of the children (Table 1). Of the total caregivers, 139(66.2\%) have good level of knowledge regarding ART with a median knowledge score of 7(IQR 6-8). All of the caregivers were able to correctly tell the right dose and frequency of pills that their children were taking. 
Table 1 Socio-demographic characteristics of caregivers and children on ART, TAH, Addis Ababa, 2012

\begin{tabular}{|c|c|c|c|}
\hline Characteristics & $\begin{array}{l}\text { Non-adherent } \\
\text { number (\%) }\end{array}$ & $\begin{array}{l}\text { Adherent } \\
\text { number (\%) }\end{array}$ & $p$-value \\
\hline \multicolumn{4}{|l|}{ Caregivers' sex } \\
\hline Male & $20(62.5)$ & $12(37.5)$ & 0.77 \\
\hline Female & $116(65.2)$ & $62(34.8)$ & \\
\hline \multicolumn{4}{|l|}{ Caregivers' age } \\
\hline $18-40$ & $83(63.4)$ & 48 (36.6) & \\
\hline $41-65$ & $38(63.3)$ & $22(36.7)$ & \\
\hline $66-90$ & $15(78.9)$ & $4(21.1)$ & 0.40 \\
\hline \multicolumn{4}{|c|}{ Caregivers' marital status } \\
\hline Single & $24(82.8)$ & $5(17.2)$ & \\
\hline Married & $48(61.5)$ & $30(38.5)$ & 0.09 \\
\hline Widowed/divorced & $64(62.1)$ & 39 (37.9) & \\
\hline \multicolumn{4}{|l|}{ Caregivers' religion } \\
\hline Orthodox & $97(66.0)$ & $50(34.0)$ & \\
\hline Muslim & $21(61.8)$ & $13(38.2)$ & \\
\hline Protestant & $18(62.1)$ & $11(37.9)$ & 0.85 \\
\hline \multicolumn{4}{|l|}{ Caregivers' education } \\
\hline Illiterate & $40(69.0)$ & $18(31.0)$ & \\
\hline Elementary education & $53(65.4)$ & $28(34.6)$ & \\
\hline Secondary and above & $43(60.6)$ & $28(39.4)$ & 0.60 \\
\hline \multicolumn{4}{|l|}{ Caregivers' occupation } \\
\hline House wife & $41(62.1)$ & $25(37.9)$ & \\
\hline Employed & $25(69.4)$ & $11(30.6)$ & 0.82 \\
\hline Daily laborer & $38(62.3)$ & $23(37.7)$ & \\
\hline Others $\neq$ & $32(68.1)$ & 15 (31.9) & \\
\hline \multicolumn{4}{|c|}{ Monthly income of care givers } \\
\hline$<30$ USD & $100(64.9)$ & $54(35.1)$ & \\
\hline$\geq 30$ USD & $36(64.3)$ & $20(35.7)$ & 0.93 \\
\hline \multicolumn{4}{|c|}{ Caregivers' relation to child } \\
\hline Biological & $76(62.8)$ & $45(37.2)$ & \\
\hline Non-biological & $60(67.4)$ & $29(32.6)$ & 0.49 \\
\hline \multicolumn{4}{|l|}{ Age of child } \\
\hline $1-5$ & $12(92.3)$ & $1(7.7)$ & \\
\hline $6-8$ & $24(60)$ & $16(40)$ & 0.09 \\
\hline $9-14$ & $100(63.7)$ & $57(36.3)$ & \\
\hline \multicolumn{4}{|l|}{ Sex of child } \\
\hline Male & $69(63.3)$ & $40(36.7)$ & \\
\hline Female & $67(66.3)$ & $34(33.7)$ & 0.65 \\
\hline \multicolumn{4}{|c|}{ Children knew their HIV status } \\
\hline Yes & $63(70.8)$ & $26(29.2)$ & \\
\hline No & $73(57.7)$ & $48(42.3)$ & 0.11 \\
\hline
\end{tabular}


Table 1 Socio-demographic characteristics of caregivers and children on ART, TAH, Addis Ababa, 2012 (Continued)

\begin{tabular}{llll}
\hline Received any support & & & \\
Yes & $52(70.3)$ & $29.7)$ & \\
No & $84(61.8)$ & $52(38.2)$ & 0.218 \\
\hline
\end{tabular}

†Exchange rate $-1 \$=17.6$ Ethiopian birr.

‡others: students, daily laborers.

\section{Social and disclosure variables of children}

One hundred and ten (52.4\%) caregivers reported that they have disclosed their children's HIV status to others (71.8\% disclosed to the family and $28.2 \%$ disclosed to the community) and $89(42.4 \%)$ disclosed to the children themselves. However, most $(82.9 \%)$ of the caregivers were not comfortable to give ART drugs to their children in the presence of others.

Seventy-four (35.2\%) of the caregivers had support (mainly as food or cash) for their children from different sources, notably from non-governmental organizations; however, only $6(8.11 \%)$ reported that they were satisfied with the support they had received. Regarding the types of regimens children have been taking, $67.6 \%$ were either on $4 \mathrm{~d}(\mathrm{AZT} / 3 \mathrm{TC} / \mathrm{EFV})$ or 4c (AZT/3TC/NVP).

\section{Clinical markers of children on ART}

The median length of time on ART was 48 months (IQR: 30-66 months). Based on review of clinical records, $79 \%$ of them were either in stage III or Stage IV of WHO classification at baseline. At the time of treatment initiation, median CD4 count was 265 (IQR: 179461) cells $/ \mathrm{mm}^{3}$ whereas the current median CD4 count was 617 (IQR: $451-855$ ) cells $/ \mathrm{mm}^{3}$. There was a significant improvement in the current CD4 count compared to the baseline CD4 count (Wilcoxon, $\mathrm{p}<001$ ). On stratifying by age, the improvement remained statistically significant [Wilcoxon, $\mathrm{p}=0.005$ ( $\leq 5$ years) and $\mathrm{p}<0.001$ (above 5 years)].

\section{Health care providers and health care system variables}

The vast majority (93.3\%) of children have been on ART for at least one year. Eighty-one percent of the caregivers reported that they had very good relationship with the health providers at the ART clinic. Furthermore, 206 (98.1\%) had open communication and got information needed from health care providers, and 208 (99.1\%) had access to the pharmacy at any day of the week. Two hundred and five of them (97.6\%) were satisfied in the scheduled appointment and 204 (97.1\%) were satisfied with their child's health improvement.

\section{Adherence to ART}

Based on caregivers' report, two-third (66.7\%) of the study participants had no history of missed doses ever and $90 \%$ had no missed doses in the last one month. A total of 196 (93.3\%) children were reported to have adherence rate of at least $95 \%$ for the past 7 days before interview. However, 96 (47.7\%) caregivers reported that medication had been taken several hours late on occasions within the last week.

On unannounced home-based pill count, only 73 (34.8\%) had adherence level of at least 95\% which is much less than the reported level of adherence (Figure 1). The level of agreement between caregivers' report and unannounced pill count was poor (kappa $=0.032$ ).

The median number of doses missed in one week was 1 (IQR: 0-2). Extra pills were counted during home visit and $37.1 \%$ of children had no extra pills, whereas $56.3 \%$ had 1 to 50 extra doses at home (Table 2). There was no significant difference in the level of adherence between those who had and who did not have extra doses at home $(\mathrm{p}=0.46)$.

When caregivers were asked regarding the type of memory aid they used, the majority (67.1\%) reported that they used a watch as memory aid for giving medication. Caregivers' forgetfulness (36.4\%) and child refusal to take medication (27.3\%) were reported to be the major reasons for missing doses and delayed ingestion of their pills (Figure 2).

On multivariate logistic regression, children with a married $[\mathrm{aOR}=7.85$ (95\% CI: 2.11, 29.13)] or widowed/ divorced caregiver $[\mathrm{aOR}=7.14(95 \% \mathrm{CI}: 2.00,25.46)]$ were more likely to adhere to their ART treatment when compared to those with single caregivers. Similarly, children who did not know their HIV sero-status were more likely to adhere to their treatment $[\mathrm{aOR}=2.35$ (95\% CI: $1.09,5.06)]$ compared to those who knew their serostatus. Those children with baseline WHO clinical stage III/IV were 2.78 times [OR $=3.18$ (95\% CI: 1. 21, 8.40)] more adherent to their ART treatment when compared to those with stage I/II. On the other hand, children on $\mathrm{d} 4 \mathrm{~T} / 3 \mathrm{Tc} / \mathrm{EFV}$ combination were less adherent than those who were on $\mathrm{d} 4 \mathrm{~T} / 3 \mathrm{Tc} / \mathrm{NVP}$ combination $[\mathrm{OR}=$ 0.10 (95\% CI: 0.02, 0.53)] (Table 3).

\section{Discussion}

Unlike previous studies in Ethiopia, this study determined the level of adherence and its predictors using unannounced home-based pill count and compared the result with caregivers' report. Based on caregivers' report, the estimated adherence rate in the last 7 days 


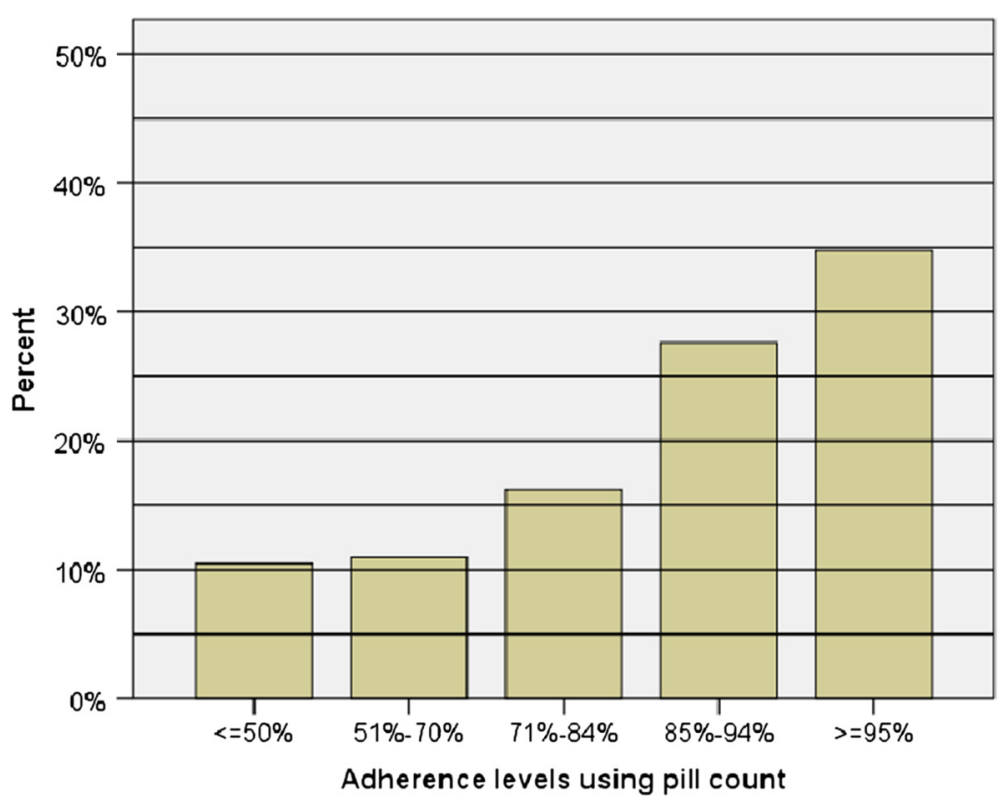

Figure 1 Children's level of adherence to ART estimated by unannounced home-based pill count, TAH, Addis Ababa, 2012.

prior to interview was $93.3 \%$, slightly higher than caregivers' reported adherence level in a similar setting [19]; however, using unannounced home-based pill count, the adherence rate $(34.8 \%)$ was unacceptably low. There is an enormous discrepancy between optimal adherence rate $(\geq 95 \%)$ estimated by caregivers' report $(93.3 \%)$ and unannounced home-based pill count (34.8\%). Similar studies elsewhere reported discrepancies between unannounced home-based pill count and caregivers' report. For example, a study in Uganda among children on ART

Table 2 Missed doses, extra doses and adherence on unannounced home-based pill count of children on ART at TAH, Addis Ababa, 2012

\begin{tabular}{ll}
\hline Characteristics & Number (\%) \\
\hline Doses missed in one week & $73(34.8)$ \\
0 & $90(42.9)$ \\
$1-2$ & $30(14.3)$ \\
$3-4$ & $17(8.1)$ \\
$>4$ & \\
Extra doses at home & $78(37.1)$ \\
0 & $52(24.8)$ \\
$1-10$ & $35(16.7)$ \\
$11-20$ & $31(14.8)$ \\
$21-50$ & $14(6.7)$ \\
$>50$ & \\
Adherence status & $137(65.2)$ \\
Non-adherent & $73(34.8)$ \\
Adherent &
\end{tabular}

reported adherence rate of $89 \%$ and 94\% using selfreport and clinic based pill count, respectively; however, on subsequent unannounced pill count, only $72 \%$ of children were found to be adherent to their treatment [24]. Similarly, a study in Tanzania [25] among adults on ART revealed that $98 \%$ and $93 \%$ of patients were adherent based on self-report and hospital pill count, respectively but only $58 \%$ were found adherent on unannounced home visit pill count. Another study from South Africa reported that objective methods gave lower levels of adherence [26] implying that subjective methods such as caregivers' report overestimate levels of adherence.

The level of adherence estimated by unannounced home-based pill count in our study is very low as opposed to many other studies. However, three studies using objective methods like medication event monitoring system (MEMS) reported very low (31-39\%) adherence rates [26-28] which are comparable to our findings. The difference in the level of adherence among studies could be explained by differences in the methods used. Almost all studies which used subjective methods reported a high level of adherence compared to those that used objective methods. Studies [26-28] have shown that high levels of adherence as measured by objective methods correlate well with virologic suppression showing that objective methods might reflect the actual level of adherence.

Children skip doses for a number of reasons. In this study, caregivers' forgetfulness was reported as a major reason (36.4\%) for skipping doses which is in agreement with other similar studies $[19,29]$. The vast majority of 


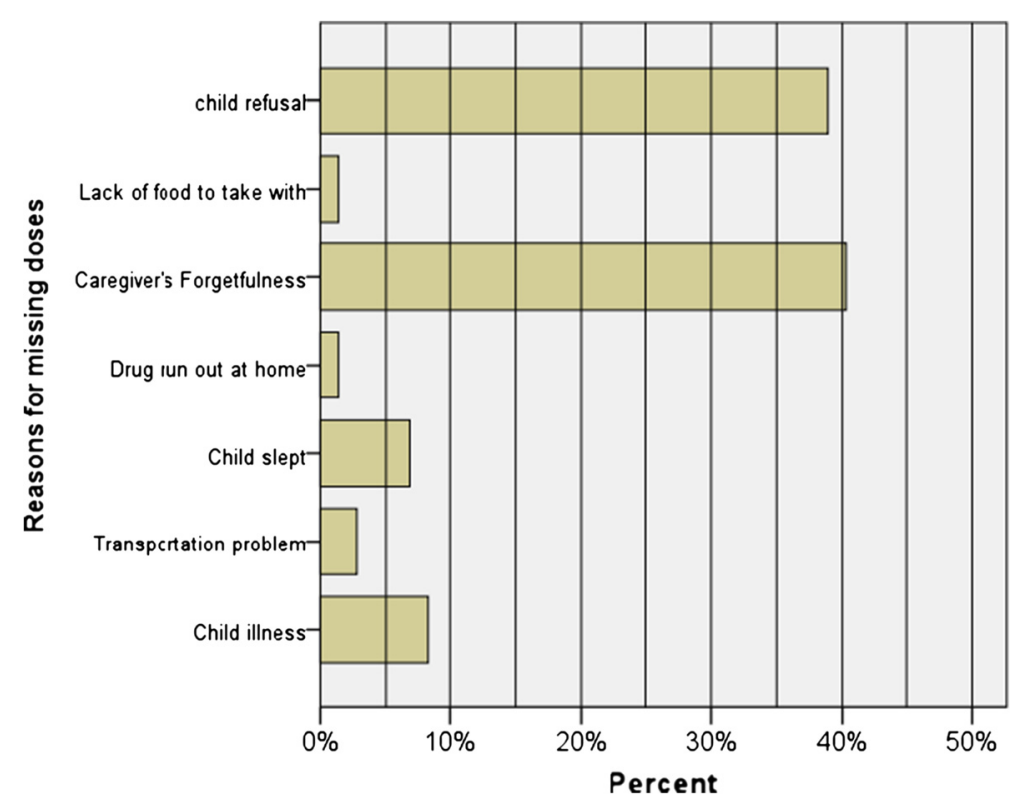

Figure 2 Reasons for missing doses mentioned by care givers of children on ART follow up at Tikur Anbessa Hospital, Addis Ababa, 2012.

the caregivers in our study were poor and amidst multiple responsibilities in meeting daily life demands, they could easily forget to make sure their children have taken their pills as scheduled. Moreover, child refusal to take medication (27.3\%) and child illness (12.1\%) were reported to be the other major reasons for skipping doses. These same reasons were mentioned in a review of studies among adults and children [6].

A number of factors have been reported as predictors of non-adherence among children on ART. In this study, children with married and widowed/divorced caregivers were significantly more adherent when compared to children with single caregivers, which is in agreement to a report from Nigeria [30]. Married caregivers might get support from their spouse in providing care to their children. Besides, widowed and divorced caregivers might be more experienced in handling children as compared to single caregivers.

The association between awareness of sero-status and adherence remains controversial. In this study like many other studies [19,31,32], children who were aware of their HIV status were less adherent than those who were not. However, other studies [15] reported that lack of disclosure of their HIV sero-status among children predicted non- adherence. Children who are aware of their sero-status might deny, feel hopelessness and skip treatment doses until they accept their HIV sero-status; and the observed difference across studies might be related to the extent and duration of counseling offered to children. Those children who have been getting regular counseling and support might accept their sero-status and be more adherent to their treatment than those who do not get proper counseling. Nevertheless, investigation of the importance of HIV sero-status disclosure to children is essential to settle these contradictory results.

The association of clinical condition of children at initiation of ART and treatment adherence is not well established. Some studies found an association between worse adherence and advanced disease [15] which is contrary to our finding. In this study, children who were in WHO stage III or IV at baseline were more adherent to their medication compared to those in stage I or II. A study from Uganda reported that those children who were hospitalized twice or more prior to starting ART had better treatment adherence levels [24]. Those children with advanced disease might be more eager to get well and this might be a motive for better adherence to their treatment.

Children taking $\mathrm{d} 4 \mathrm{~T} / 3 \mathrm{Tc} / \mathrm{EFV}$ combination were less likely to adhere than those children on $d 4 \mathrm{~T} / 3 \mathrm{Tc} / \mathrm{NVP}$ combination. Although every drug has its own adverse effect, lower adherence on children on Efavirenz combination in this study is probably due to its serious side effects including neuropsychological symptoms, such as bad dreams, dizziness, depression, anxiety, hallucinations, aggressive behavior, and suicidal ideation [33].

A cross-sectional study design was employed in this study and its limitations especially recall bias should be appreciated. Besides, participants were included consecutively when they came for their regular clinic appointment and this might have introduced selection bias. This study was done in a season of holidays that 
Table 3 Predictors of ART adherence among children at TAH, Addis Ababa, 2012

\begin{tabular}{|c|c|c|c|c|}
\hline Characteristics & $\begin{array}{l}\text { Non-adherent } \\
\text { number }\end{array}$ & $\begin{array}{l}\text { Adherent } \\
\text { number }\end{array}$ & $\begin{array}{c}\text { Crude OR } \\
(95 \% \mathrm{Cl})\end{array}$ & $\begin{array}{l}\text { Adjusted OR } \\
(95 \% \mathrm{Cl})\end{array}$ \\
\hline \multicolumn{5}{|c|}{ Care givers' marital status } \\
\hline Single & 24 & 5 & Reference & Reference \\
\hline Married & 48 & 30 & $3.00(1.03,8.71)$ & $7.85(2.11,29.13)^{*}$ \\
\hline Widowed/ Divorced & 64 & 39 & $2.93(1.03,8.30)$ & $7.14(2.00,25.46)^{*}$ \\
\hline \multicolumn{5}{|c|}{ Children knew their HIV status } \\
\hline Yes & 63 & 26 & Reference & Reference \\
\hline No & 73 & 48 & $1.59(0.89,2.86)$ & $2.35(1.09,5.06)^{*}$ \\
\hline \multicolumn{5}{|l|}{ Regimen type } \\
\hline $4 \mathrm{a}=\mathrm{d} 4 \mathrm{~T} / 3 \mathrm{TC} / \mathrm{NVP}$ & 26 & 14 & Reference & Reference \\
\hline $4 \mathrm{~b}=\mathrm{d} 4 \mathrm{~T} / 3 \mathrm{TC} / \mathrm{EFV}$ & 17 & 2 & $0.22(0.04,1.09)$ & $0.10(0.02,0.53)^{*}$ \\
\hline $4 \mathrm{C}=\mathrm{AZT} / 3 \mathrm{TC} / \mathrm{NVP}$ & 32 & 26 & $1.51(0.66,3.46)$ & $1.50(0.54,4.13)$ \\
\hline $4 \mathrm{~d}=\mathrm{AZT} / 3 \mathrm{TC} / \mathrm{EFV}$ & 53 & 31 & $1.09(0.50,2.39)$ & $0.63(0.24,1.67)$ \\
\hline Others\$ & 8 & 1 & $0.23(0.03,2.05)$ & $0.11(0.01,1.23)$ \\
\hline \multicolumn{5}{|l|}{ Duration on ART } \\
\hline$<12$ months & 13 & 1 & Reference & Reference \\
\hline$\geq 12$ months & 123 & 73 & $7.71(0.99,60.20)$ & $8.37(0.91,77.32)$ \\
\hline \multicolumn{5}{|l|}{ Baseline WHO stage } \\
\hline Stage I and || & 34 & 10 & Reference & Reference \\
\hline Stage III and IV & 102 & 64 & $2.13(0.99,4.61)$ & $3.18(1,21,8.40)^{*}$ \\
\hline \multicolumn{5}{|l|}{ Baseline CD4 } \\
\hline$\leq 200$ & 44 & 25 & Reference & Reference \\
\hline $201-500$ & 60 & 37 & $1.09(0.57,2.06)$ & $0.81(0.37,1.75)$ \\
\hline$>500$ & 32 & 12 & $0.66(0.29,1.51)$ & $0.37(0.13,1.03)$ \\
\hline
\end{tabular}

p $<0.05$.

OR odds ratio.

$\mathrm{Cl}$ confidence interval.

Variables included in the logistic regression model were age and sex of child, caregivers' age, caregivers' sex, caregivers' education and income. \$Others: $A B C / d d i / L P v / r, A Z T / 3 T c / L P v / r$ and D4T/3TC/LPv/r.

brings families together. Caregivers might be reluctant to give medications to their children in front of others to avoid stigma and this might have underestimated the level of adherence. In this study, it was not possible to assess the clinical relevance of adherence among children. Besides, a point adherence level may not reflect the actual long term adherence, implying the need for longitudinal studies.

\section{Conclusion}

In this study, there was a major difference in the level of adherence estimated by caregivers' report and unannounced home-based pill count. The level of adherence estimated by unannounced home-based pill count was found to be unacceptably low. Interventions towards improving adherence to ART among children at TAH are urgently needed. Moreover, children with single caregivers, those who were aware of their sero-status, those with baseline WHO clinical stage I/II and those on $\mathrm{d} 4 \mathrm{t} / 3 \mathrm{TC} / \mathrm{EFV}$ combination need special attention to improve their level of adherence to their medication.

A longitudinal study measuring adherence combined with clinical parameters (viral load and CD4 count) is needed to identify a simple and reliable measure of adherence in the study area.

\section{Competing interests}

The authors declare that they have no competing interests.

\section{Authors' contributions}

SB was involved in the design, data collection and analysis. MB conceived the study, participated in its design \& analysis and drafted the manuscript. WEA participated in the design of the study and data analysis. MA and WAT were involved in the acquisition of data. All authors have critically reviewed and approved the final manuscript.

\section{Acknowledgements}

We would like to thank Dr. Girmay Medhin, a biostastician/epidemiologist from Aklilu Lemma Institute of Pathobiology for his valuable advice in the data analysis. We thank Dr. Hailom Banteyirga, an academic staff of Addis Ababa University, College of Humanities, Language Studies, Communication, and Journalism, for editing the manuscript. We appreciate the support we 
got from staff members of Pediatric ART Clinic of TAH during data collection. Nurse Ekram Mehafuz is duly acknowledged for collecting the data. Finally, we would like to express our sincere gratitude to the caregivers and their children for consenting to participate in this study. This study was financed by Addis Ababa University and Armauer Hansen Research Institute.

\section{Author details}

${ }^{1} T$ Tikur Anbessa Hospital, Addis Ababa University, P.O. Box 1176, Addis Ababa, Ethiopia. ${ }^{2}$ Aklilu Lemma Institute of Pathobiology, Addis Ababa University, P.O. Box 1176, Addis Ababa, Ethiopia. ${ }^{3}$ Armauer Hansen Research Institute, P.O. Box 1005, Addis Ababa, Ethiopia. ${ }^{4}$ Department of Pediatrics, School of Medicine, Addis Ababa University, P.O. Box 1176, Addis Ababa, Ethiopia.

Received: 8 May 2013 Accepted: 28 August 2013

Published: 2 September 2013

\section{References}

1. UNAIDS: GLOBAL HIVIAIDS RESPONSE: Epidemic update and health sector progress towards Universal Access, Progress Report; 2011.

2. Ministry of Health of Ethiopia and Federal HIV/AIDS Prevention and Control Office: Guidelines for implementation of HIV/AIDS case management in Ethiopia. Addis Ababa; 2009.

3. Isaakidis P, Raguenaud M, Te V, Tray CS, Akao K, Kumar V, Ngin S, Nerrienet E, Zachariah R: High survival and treatment success sustained after two and three years of first-line ART for children in Cambodia. J Int AIDS Soc 2010, 13:11.

4. Raguenaud ME, Isaakidis P, Zachariah R, Te V, Soeung S, Akao K, Kumar V: Excellent outcomes among HIV + children on ART, but unacceptably high pre-ART mortality and losses to follow-up: a cohort study from Cambodia. BMC Pediatr 2009, 9:54.

5. Davies M, Keiser O, Technau K, Eley B, Rabie H, Cutsem GV, Giddy J, Wood R, Boulle A, Egger M, Moultrie H: Outcomes of the South African National Antiretroviral Treatment Programme for children: the leDEA Southern Africa collaboration. S Afr Med J 2009, 99(10):730-737.

6. Shah CA: Adherence to high activity Antiretroviral Therapy (HAART) in pediatric patients infected with HIV: Issues and interventions. Indian J Pediatr 2007, 74(1):55-60.

7. Patel A, Trivedi SS, Chudasama RK, Patel PK: Effect of antiretroviral therapy on clinical and immunologic disease progression in HIV positive children: One-year follow-up study. J Fam Community Med 2012, 19(3):178-183

8. Dijk JHV, Sutcliffe CG, Munsanje B, Sinywimaanzi P, Hamangaba F, Thuma PE, Moss WJ: HIV infected children in rural Zambia achieve good immunologic and virologic outcomes Two years after initiating antiretroviral therapy. PLoS One 2011, 6(4):e19006.

9. Osterberg L, Blaschke T: Adherence to medication. N Engl J Med 2005, 353:487-497.

10. Zoufaly A, Fillekes Q, Hammerl R, Nassimi N, Jochum J, Drexler JF, Awasom CN, Sunjoh F, Burchard GD, Burger DM, van Lunzen J, Feldt T: Prevalence and determinants of virological failure in HIV-infected children on antiretroviral therapy in rural Cameroon: a cross-sectional study. Antivir Ther 2013. doi:10.3851/IMP2562.

11. Orrell C, Bangsberga DR, Badri M, Wood R: Adherence is not a barrier to successful antiretroviral therapy in South Africa. AIDS 2003, 17:1369-1375.

12. Abaasa AM, Todd J, Ekoru K, Kalyango JN, Levin J, Odeke E, Karamagi CAS: Good adherence to HAART and improved survival in a community HIV/ AIDS treatment and care programme: the experience of The AIDS Support Organization (TASO), Kampala, Uganda. BMC Health Serv Res 2008, 8:241.

13. Rath BA, Kleist MV, Castillo ME, Kolevic L, Caballero P, Soto-Castellares G, Amedee AM, Robinson JE, Katzenstein DK, Dyke RBV, Oberhelman RA: Antiviral resistance and correlates of virologic failure in the first cohort of HIV-infected children gaining access to structured Antiretroviralm Therapy in Lima, Peru: a cross-sectional analysis. BMC Infect Dis 2013, 13:1.

14. Barth RE, Tempelman HA, Smelt E, Wensing AMJ, Hoepelman Al, Geelen SP: Long-term outcome of children receiving antiretroviral treatment in rural South Africa: substantial virologic failure on first-line treatment. Pediatr Infect Dis J 2011, 30:52-56.

15. Haberer J, Mellins C: Pediatric adherence to HIV Antiretroviral Therapy. Curr HIV/AIDS Rep 2009, 6(4):194-200.
16. Ministry of Health of Ethiopia and Federal HIV/AIDS Prevention and Control Office: Guidelines for Pediatric HIV/AIDS Care and Treatment in Ethiopia. Addis Ababa; 2008

17. WHO: Antiretroviral therapy of HIV infection in infants and children: towards universal access. Switzerland: WHO; 2006.

18. Vreeman RC, Wiehe SE, Pearce EC, Nyandiko WM: A systematic review of pediatric adherence to Antiretroviral Therapy in low- and middle-income countries. Pediatr Infect Dis J 2008, 27:686-691.

19. Biadgilign S, Deribew A, Amberbir A, Deribe K: Adherence to highly active antiretroviral therapy and its correlates among HIV infected pediatric patients in Ethiopia. BMC Pediatr 2008, 8:53.

20. Tessema B, Biadglegne F, Mulu A, Getachew A, Emmrich F, Sack U: Magnitude and determinants of non adherence and non readiness to highly active antiretroviral therapy among people living with HIV/AIDS in Northwest Ethiopia. AIDS Res Ther 2010, 7:2

21. Tiyou A, Belachew T, Alemseged F, Biadgilign S: Predictors of adherence to antiretroviral therapy among people living with HIV/AIDS in resourcelimited setting of South-West Ethiopia. AIDS Res Ther 2010, 7:39.

22. Lee JK, Grace KA, Foster TG, Crawley MJ, Erowele GI, Sun HJ, Turner PT, Sullenberger $L E$, Taylor AJ: How should we measure medication adherence in clinical trials and practice? Ther Clin Risk Manag 2007. 3(4):685-690.

23. Paterson DL, Swindells S, Mohr J, Brester M, Vergis EN, Squier C, Wagener $M M$, Singh N: Adherence to protease inhibitor therapy and outcomes in patients with HIV infection. Ann Intern Med 2000, 133:21-30.

24. Nabukeera-Barungi N, Kalyesubula I, Kekitiinwa A, Byakika-Tusiime J, Musoke $P:$ Adherence to antiretroviral therapy in children attending Mulago Hospital, Kampala. Ann Trop Paediatr 2007, 27(2):123-131.

25. Minzi OM, Naazneen AS: Validation of self-report and hospital pill count using unannounced home pill count as methods for determination of adherence to antiretroviral therapy. Tanzan J Health Res 2008, 10(2):84-88.

26. Müller AD, Jaspan HB, Myer L, Hunter AS, Hurling G, Bekker LG, Orrell C: Standard measures are inadequate to monitor pediatric adherence in a resource-limited setting. AIDS Behav 2011, 15(2):422-431.

27. Müller AD, Bode S, Myer L, Stahl J, Steinbüchel NV: Predictors of adherence to antiretroviral treatment and therapeutic success among children in South Africa. AIDS Care 2011, 23(2):129-138.

28. Farley J, Hines S, Musk A, Ferrus S, Tepper V: Assessment of adherence to antiretroviral therpay in HIV-infected children using the medication event monitoring system, pharmacy refill, provider assessment, caregiver self-report and appointment keeping. JAIDS 2003, 33:211-218,

29. Polisset J, Ametonou F, Arrive E, Aho A, Perez F: Correlates of adherence to Antiretroviral Therapy in HIV-infected children in Lome, Togo, West Africa. AIDS Behav 2009, 13:23-32

30. Uzochukwu BSC, Onwujekwe OE, Onoka AC, Okoli C, Uguru NP, Chukwuogo Ol: Determinants of non-adherence to subsidized antiretroviral treatment in southeast Nigeria. Health Policy Plan 2009, 24(3):189-196.

31. Giacomet V, Albano F, Starace F, de Franciscis A, Giaquinto C, Gattinara GC, Bruzzese E, Gabiano C, Galli L, Viganò A, Caselli D, Guarino A: Adherence to antiretroviral therapy and its determinants in children with human immunodeficiency virus infection: a multicentre, national study. Acta Paediatr 2003, 92(12):1398-1402.

32. Marhefka SL, Tepper VJ, Brown JL, Farley JJ: Caregiver psychosocial characteristics and children's adherence to antiretroviral therapy. AIDS Patient Care STDS 2006, 20:429-437.

33. Wichers $M$, Ven AVD, Maes $M$ : Central nervous system symptoms related to the use of efavirenz in HIV-seropositive patients. Curr Opin Psychiatry 2002, 15:643-647.

doi:10.1186/1471-2431-13-132

Cite this article as: Biressaw et al:: Adherence to Antiretroviral Therapy and associated factors among HIV infected children in Ethiopia: unannounced home-based pill count versus caregivers' report. $B M C$ Pediatrics 2013 13:132. 